\title{
Sarcoidosis presenting as multiple pulmonary nodules and nephrotic syndrome
}

\author{
Francesc Vidal $^{1}$, J.A. Oliver ${ }^{2}$, Encarnació Campanya ${ }^{1}$, Alfonso Baguer ${ }^{1}$, Marta \\ Carrera $^{3}$ and Cristobal Richart ${ }^{1}$
}

${ }^{1}$ Servei de Medicina Interna and ${ }^{2}$ Secció de Nefrologia, Hospital Joan XXIII, Tarragona, Departament de
Patologia i Clinica Médiques, Facultat de Medicina (extensió Reus), Universitat de Barcelona and ${ }^{3}$ Servei
d'Anatomia Patológica, Hospital de Bellvitge 'Princeps d'Espanya', L'Hospitalet del Llobregat, Barcelona, Spain

Summary: A 56 year old man presented with thrombophlebitis, nephrotic range proteinuria and multiple pulmonary nodules. A renal biopsy showed membranous glomerulonephritis, and after a thoracotomy a diagnosis of sarcoidosis was established.

A pulmonary nodular pattern is unusual in sarcoidosis and is often mistaken for malignant disease. The association of this type of pulmonary involvement and membranous glomerulonephritis as the presenting form of sarcoidosis has not previously been described.

\section{Introduction}

Sarcoidosis is a disease that involves multiple systems and presents a variety of clinical syndromes (Mayock et al., 1963).

The chest X-ray of patients with sarcoidosis can be normal, show hilar lymphadenopathy or diffuse parenchymal involvement (Felson, 1959). Multiple pulmonary nodules are infrequently seen (Felson, 1959; Sharma et al., 1973; McCord \& Hyman, 1952).

Renal involvement in sarcoidosis is also uncommon and usually attributed to calcium nephropathy, sarcoid interstitial nephritis (direct granulomatous involvement) or associated glomerulonephritis, usually of the membranous type (Muther et al., 1981).

We report here an unusual case of a patient with sarcoidosis who presented initially with multiple pulmonary nodules and membranous glomerulonephritis. To our knowledge there are no previous reports of this association as the presenting form of sarcoidosis.

\section{Case report}

A 56 year old man, who in his twenties worked as a miner, was considered disabled because of asthma and joint stiffness that improved with steroids.

In 1984 he was admitted to the hospital with thrombophlebitis of his left leg. Proteinuria $(2 \mathrm{~g} / 24 \mathrm{~h})$ was present and serum transaminases were all

Correspondence: F. Vidal, M.D.

Accepted: 19 June 1986 elevated. Multiple pulmonary nodules were seen on the chest X-ray (Figure 1). Arterial blood gases were normal and a ventilation-perfusion lung scan ruled out pulmonary embolus. A liver and spleen scan disclosed a uniformly enlarged liver and increased concentration of the radionuclide. The patient was treated with heparin and was discharged with a presumptive diagnosis of metastatic lung neoplasm.

One month later he was readmitted to the hospital because of fever. The chest X-ray showed a right basal pneumonia and the same nodular pattern. Laboratory tests showed a urinary protein excretion of $4 \mathrm{~g} / 24 \mathrm{~h}$. Serum albumin was $25 \mathrm{~g} / \mathrm{dl}$ and serum creatinine was $80 \mathrm{mmol} / \mathrm{dl}$. Circulating immune complexes (polyethylene-glycol-ELISA) and angiotensin converting enzyme were both normal.

Renal biopsy showed membranous glomerulonephritis. Granular and focal deposits of IgG, IgA and $\mathrm{C} 3$ in the basement membrane were demonstrated by immunofluorescence. An open pulmonary biopsy showed granulomas with epithelioid giant cells and no caseation. Special stains showed no acid-fast bacilli. A liver biopsy was normal.

A diagnosis of sarcoidosis was established and the patient was placed on prednisone $60 \mathrm{mg} /$ day. The pulmonary nodules cleared after 3 months' treatment but the nephrotic syndrome was unchanged.

\section{Discussion}

The intrathoracic presentation of sarcoidosis has been 

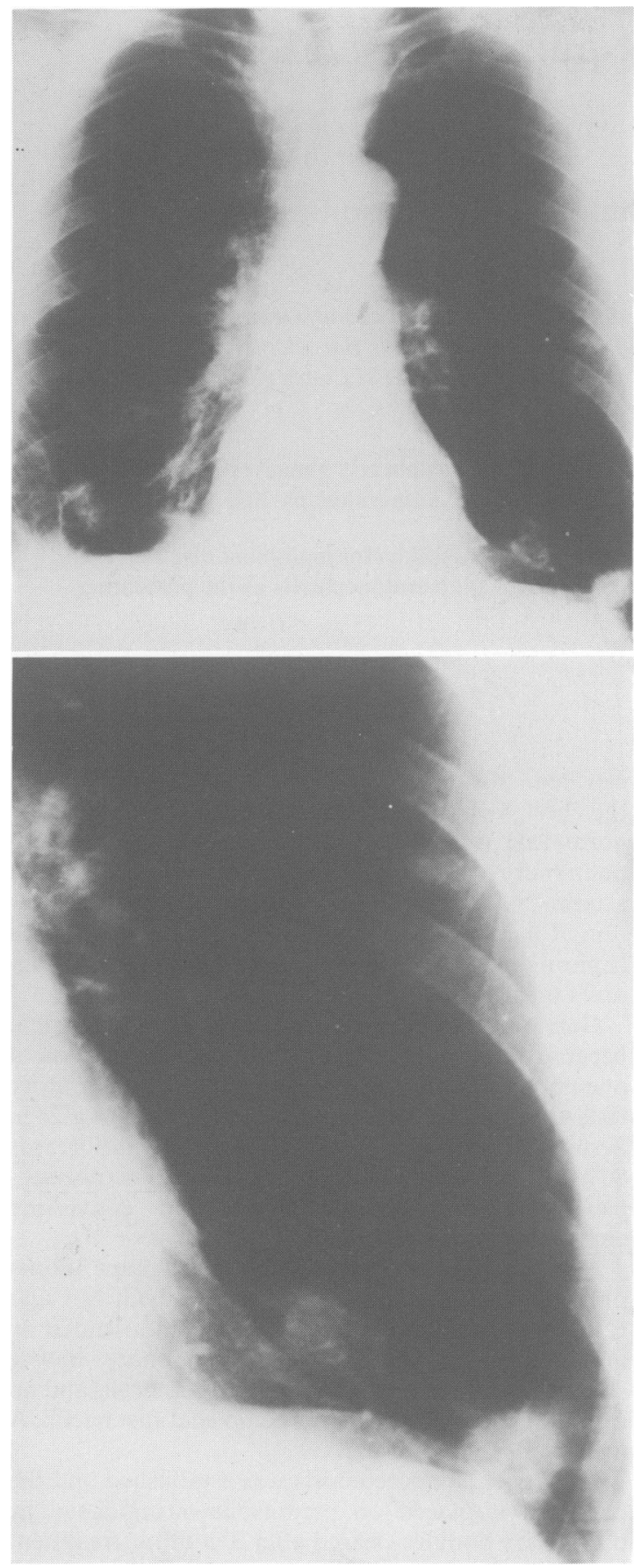

Figure 1 Chest $\mathrm{X}$-ray showing multiple pulmonary nodules. divided into four stages: (I) Bilateral hilar and right paratracheal lymph node enlargement; (II) persistence of enlarged lymph nodes with concomitant pulmonary infiltration; (III) parenchymal involvement with no identifiable mediastinal adenopathy, and (IV) fibrotic lungs with bullae (Sharma et al., 1973; Kirks et al., 1973). The parenchymal infiltrations seen in stages II and III appear in a variety of patterns. The pulmonary densities are almost bilateral and may be reticulonodular or confluent, or may present as multiple large densities simulating metastatic carcinoma (Littner et al., 1977).

Multiple pulmonary nodules are fairly uncommon in sarcoidosis (Sharma et al., 1973). The first case was $\stackrel{\circ}{\sigma}$ reported in 1952 by McCord \& Hyman. Since then a $\underset{8}{8}$ few reports of this X-ray pattern have been published 3 . usually in women and blacks (Felson, 1959; Sharma et al., 1973; McCord \& Hyman, 1952; Kirks et al., 1973; Littner et al., 1977; Dhakhwa et al., 1976). Its $\underset{\perp}{\stackrel{\omega}{ }}$ frequency in the different series varies from 0 to $4 \%$ (Mayock et al., 1963; Sharma et al., 1973). This $\vec{\nexists}$ pattern of lung involvement can be mistaken for

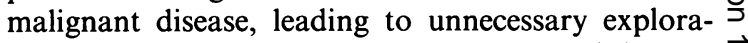
tions searching for neoplasm as occurred in our $\vec{\nabla}$ patient. Against the diagnosis of malignant disease are $\mathbb{D}$ the usually good general condition of the patients $\stackrel{\mathbb{D}}{\rightarrow}$ despite the extensive lung involvement and the slow progression of the pulmonary lesions (Felson, 1959 1

In the first cases reported, tissue biopsy for hi $\overrightarrow{0}$ tological diagnosis was obtained from superficia lymph nodes and from the lungs, by means of open lung biopsy (Felson, 1959; McCord et al., 1952). In the more recent cases reported, transbronchial lung biopsy has been the diagnostic method of choice (Dhakwa et al., 1976). In our patient neither transbronchial nor percutaneous lung biopsy were succesful and an open lung biopsy was carried out.

The renal lesion in this patient was a membranous glomerulonephritis. This is the most common type of glomerular involvement in sarcoidosis (McCoy \& Tisher, 1972; Mariani et al., 1978; Muther et al., 1981; Kent Taylor et al., 1979), and it has been attributed to immunity alterations in this disease. The reason for the preference for membranous lesion in sarcoidosis is unknown (Taylor et al., 1982).

The corticosteroid resistance of sarcoidosis glomerulonephritis shown by our patient has been reported by several authors (Muther et al., 1981; McCoy et al., 1972; Taylor et al., 1982). 


\section{References}

DHAKHWA, R.B., HARMAN, E. \& SAFIRSTEIN, B.H. (1976). Sarcoidosis presenting as multiple pulmonary nodes. Journal of the American Medical Association, 236, 2529.

FELSON, B. (1959). Less familiar roentgen patterns of pulmonary granulomas. Sarcoidosis, histoplasmosis and noninfectious necrotizing granulomatosis (Wegener's syndrome). American Journal of Roentgenology, Radium Therapy, and Nuclear Medicine, 81, 211.

KENT TAYLOR, T., SENEKJIAN, H.O., KNIGHT, T.F., GYORKEY, F. \& WEINMAN, E.J. (1979). Membranous nephropathy with epithelial crescents in a patient with pulmonary sarcoidosis. Archives of Internal Medicine, 139, 1183.

KIRKS, D.R., MCCORMICK, U.D. \& GREENSPAN, R.H. (1973). Pulmonary sarcoidosis. Roentgenologic analysis of 150 patients. American Journal of Roentgenology, Radium Therapy and Nuclear Medicine, 117, 777.

LITTNER, M.R., NEIL SCHACHTER, E., PUTMAN, Ch.E., ODERO, D.O. \& GEE, J.B.L. (1977). The clinical assessment of roentgenographically atypical pulmonary sarcoidosis. American Journal of Medicine, 62, 361.

MARIANI, A.F., CLIFTON, S., DAVIES, D.J., DAWBORN, J.K., FITZGERALD, J.E., IHLE, B.U., NIALL, J.F. \& RYAN, G.B. (1978). Membranous glomerulonephritis associated with sarcoidosis. Australia and New Zealand Journal of Medicine, 8, 420.

MAYOCK, R.L., BERTRAND, P., MORRISON, C.E. \& SCOTT, J.H. (1963). Manifestations of sarcoidosis. Analysis of 145 patients with review of nine series selected from the literature. American Journal of Medicine, 35, 67.

MCCORD, M.C. \& HYMAN, H.L. (1952). Pulmonary sarcoidosis with the roentgenologic appearances of metastatic neoplasm. A report of two cases. American Journal of Roentgenology, Radium Therapy and Nuclear Medicine, 67, 259.

MCCOY, R.C. \& TISHER, C.C. (1972). Glomerulonephritis associated with sarcoidosis. American Journal of Pathology, 68, 339.

MUTHER, R.S., MCCARRON, D.A. \& BENNETT, W.M. (1981). Renal manifestations of sarcoidosis. Archives of Internal Medicine, 141, 643.

SHARMA, O.P., HEWLETT, R. \& GORDONSON, J. (1973). Nodular sarcoidosis: an unusual radiographic appearance. Chest, 64, 189.

TAYLOR, R.G., FISHER, C. \& HOFFBRAND, B.I. (1982). Sarcoidosis and membranous glomerulonephritis: a significant association. British Medical Journal, 284, 1297. 